\title{
SPECTROPHOTOMETRIC AND FLUORIMETRIC METHODS FOR DETERMINATION OF NALTREXONE IN URINE, SERUM AND TABLETS BY OXIDATION WITH CERIUM (IV)
}

\author{
AKRAM M. EL-DIDAMONY,† WAFAA S. HASSAN \\ ${ }^{I}$ Chemistry Department, Faculty of Science, Zagazig University, Zagazig, Egypt \\ ${ }^{2}$ Department of Analytical Chemistry, Faculty of Pharmacy, Zagazig University; Zagazig, Egypt \\ Corresponding author: Tel.: +20 552277596 . \\ (Received: April 20, 2012 - Accepted: July 26, 2012)
}

\begin{abstract}
This paper proposes new methods for simple and sensitive spectrophotometric and fluorimetric determination of naltrexone (NALT) in tablet and biological fluids. The spectrophotometric method involve addition of a known excess of Ce(IV) to NALT in acid medium, followed by determination of residual Ce(IV) by reacting with a fixed amount of methyl orange, and measuring the absorbance at $510 \mathrm{~nm}$. Fluorimetric method was based on the oxidation of NALT with Ce(IV) to produce $\mathrm{Ce}(\mathrm{III})$ and its fluorescence was monitored at $350 \mathrm{~nm}$ after excitation at $250 \mathrm{~nm}$. In both methods, the amount of Ce(IV) reacted corresponds to the amount of NALT and the measured absorbance or fluorescence were found to increase linearly with the concentration of NALT, which are corroborated by the correlation coefficients of 0.9999 and 0.9996 for spectrophotometric and fluorimetric methods, respectively. Different variables affecting the reaction conditions such as the concentrations of $\mathrm{Ce}(\mathrm{IV})$, type and concentration of acid medium, reaction time, temperature, and the diluting solvents were carefully studied and optimized. The accuracy and precision of the methods were evaluated on intra-day and inter-day basis. The proposed methods were successfully applied for the determination of NALT in pharmaceutical formulation and biological samples with good recoveries.
\end{abstract}

Keywords: Spectrophotometric, fluorimetric, naltrexone, dosage form, Ce(IV).

\section{INTRODUCTION}

Opiate addiction is a very serious worldwide problem which has now spread to societies. ${ }^{1}$ One of the current treatments is to use narcotic antagonists which generally have chemical structures similar to those of opiates and can preferentially occupy the body's opiate receptors and thus block their euphoric effects. This makes opiate intake delight less and removes the addicts' incentive in opiate using. ${ }^{2}$ Naltrexone (Fig. 1), (17-(cyclopropylmethyl)-4,5a-epoxy3,14-dihydroxymorphinan-6-one) is a long-acting synthetic opiate antagonist with few side effects that is efficacious when administered orally, either daily or three times a week for a sustained period of time.

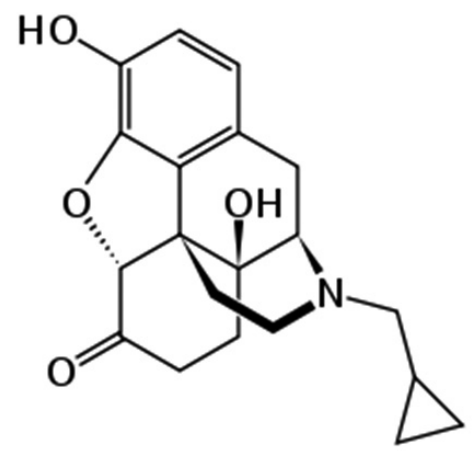

Fig. 1. Chemical structure of naltrexone.

Naltrexone has been determined by using a wide variety of analytical techniques, particularly chromatographic, such as thin-layer chromatography, ${ }^{3}$ high-performance liquid chromatography (HPLC) with electrochemical detection, ${ }^{4-8}$ gas chromatography, ${ }^{9,10}$ and gas chromatography coupled with mass spectrometry (MS). ${ }^{11}$ The latest developments use liquid chromatography (LC) with MS detection ${ }^{12}$ and LC-MS/MS, ${ }^{13,14}$ primarily for determination of naltrexone in animal plasma. Existing methods use time-consuming off-line sample cleanup ${ }^{5-8,13,14}$ including liquid-phase or solid-phase extraction steps, which is disadvantageous for a routine therapeutic drug monitoring (TDM) survey aiming to report results within a single day after blood withdraw. ${ }^{15}$

In the analytical literature reviewed for naltrexone, no up to date, references were described utilizing spectrophotometric and fluorimetric techniques for the quantitation of naltrexone. Therefore, our goal was to develop a validated spectrophotometric and fluorimetric methods which needs minimum sample preparation and has sufficiently low limit of quantification. The present paper describes two methods, spectrophotometric and fluorimetric, for the determination of naltrexone after its reaction with $\mathrm{Ce}(\mathrm{IV})$ in acid medium.

\section{EXPERIMENTAL}

\section{Apparatus}

Spectrofluorimetric measurements were carried out on a Shimadzu RF5301 PC spectrofluorimeter (Kyoto, Japan), equipped with a $150 \mathrm{~W}$ xenon lamp and using $1.0 \mathrm{~cm}$ quartz cells. The excitation and emission monochromators were fixed with $1.5 \mathrm{~mm}$ slits.

Spectroscan $80 \mathrm{D}$ double-beam UV/Visible spectrophotometer (Biotech Engineering Ltd. (UK)), with wavelength range $190 \mathrm{~nm} \sim 1100 \mathrm{~nm}$, spectral bandwidth $2.0 \mathrm{~nm}$, with $10 \mathrm{~mm}$ matched quartz cells was used for all spectrophotometric measurements.

\section{Solutions}

i. Standard drug solution was prepared by dissolving $20 \mathrm{mg}$ of naltrexone hydrochloride (NALT) in $100 \mathrm{~mL}$ of distilled water. The analytical standard solutions of NALT were prepared daily by appropriate dilution of the stock standard solution in water. Pharmaceutical grade naltrexone hydrochloride was received from the Egyptian International Pharmaceutical Industries Company (EIPICo), Cairo, which was reported to be $99.8 \%$ purity, as gift and was used as received. NALT is soluble in distilled water; therefore distilled water may be used as solvent.

ii. $\quad \mathrm{Ce}(\mathrm{IV})$ solution at concentration of $5.0 \times 10^{-3} \mathrm{M}$ was prepared from cerric ammonium sulphate in $1.0 \mathrm{M}$ sulphuric acid and was kept in the refrigerator at $4^{\circ} \mathrm{C}$ for two weeks.

iii. A $1.0 \times 10^{-3} \mathrm{M}$ of methyl orange was prepared by dissolving the accurate weighed amount of $0.0327 \mathrm{~g}$ in $100 \mathrm{~mL}$ water.

iv. A $1.0 \mathrm{M}$ sulphuric acid was prepared.

All other reagents were of analytical reagents grade and all solutions were prepared in distilled water.

\section{Procedure for Calibration Curves}

Spectrophotometric method

Different aliquots $(0.2-1.4 \mathrm{~mL})$ of $\left(200 \mu \mathrm{g} \mathrm{mL} \mathrm{mL}^{-1}\right)$ NALT were transferred into a series of $25-\mathrm{mL}$ calibrated flasks. Then, $2.0 \mathrm{~mL}$ of $1.0 \mathrm{M} \mathrm{H}_{2} \mathrm{SO}_{4}$ was added followed by $0.8 \mathrm{~mL}$ of $5 \times 10^{-3} \mathrm{M} \mathrm{Ce}(\mathrm{VI})$. The contents were shaken well and were set aside for $10 \mathrm{~min}$ with occasional shaking. Finally, $1.4 \mathrm{~mL}$ of $1.0 \times 10^{-3} \mathrm{M}$ methyl orange was added to each flask, the volume was adjusted up to the mark with distilled water and mixed well. The absorbance of each solution was measured at $510 \mathrm{~nm}$ against the corresponding reagent blank.

Fluorimetric method

To a set of $10-\mathrm{mL}$ test tubes, solutions were added in the following order: 
$1.0 \mathrm{~mL}$ of $5 \times 10^{-3} \mathrm{M} \mathrm{Ce}(\mathrm{VI}), 2.0 \mathrm{~mL}$ of $1.0 \mathrm{M} \mathrm{H}_{2} \mathrm{SO}_{4}$ and $(0.1-0.7 \mathrm{~mL}$ aliquots of $100 \mu \mathrm{g} \mathrm{mL}^{-1}$ NALT standard working solution. The mixtures were heated in a thermostated water-bath at $100^{\circ} \mathrm{C}$ for $25 \mathrm{~min}$, cooled to room temperature and transferred quantitatively into a set of $25-\mathrm{mL}$ measuring flasks and diluted to the mark with bidistilled water. The fluorescence intensity was measured for the reaction solution at emission wavelength of $350 \mathrm{~nm}$ with the excitation wavelength at $250 \mathrm{~nm}$ and plotted against the concentration of NALT to obtain the standard calibration graph.

\section{Procedure for tablets}

Ten tablets of deltrexone (Manufactured by Delta Pharmaceuticals Co., Egypt) each containing $50 \mathrm{mg}$ of NALT were completely powdered. An accurately weighed portion, equivalent to $20 \mathrm{mg}$ was dissolved in about $10 \mathrm{~mL}$ of bidistilled water and any remaining residue was removed by filtration. The filtered solution was then transferred into a $100 \mathrm{~mL}$ calibrated flask and diluted to $100 \mathrm{~mL}$ with water. Suitable dilution was made to fit the applicable concentration range and the above described procedures were followed. The nominal content of the tablet was assayed from the calibration curves.

Procedure for spiked biological fluids

$1.0 \mathrm{~mL}$ serum sample was deproteinized by adding $5 \mathrm{~mL}$ acetonitrile, in a centrifuge tube, which was then centrifuged for $5 \mathrm{~min}$ at $2500 \mathrm{rpm}$. The supernatant was diluted with distilled water to suitable concentration. Spiked urine was 50 -fold diluted with distilled water. The treated serum and urine samples were spiked with convenient amounts of NALT stock solutions. Human serum and urine were kindly provided by healthy volunteers.

\section{RESULTS AND DISCUSSION}

\section{Optimization of Reaction Conditions}

Investigations were carried out to establish the most favorable conditions for the oxidation. The parameters optimized included the effect of $\mathrm{Ce}(\mathrm{IV})$ concentration, heating temperature and time were investigated.

\section{Spectrophotometric Method}

\section{Effect of $\mathrm{Ce}(\mathrm{IV})$ concentration}

The influence of $\mathrm{Ce}(\mathrm{IV})$ concentration on the color intensity of the reaction product was studied using increasing volumes of $5 \times 10^{-3} \mathrm{M} \mathrm{Ce}$ (IV) solution. It was found that maximum and constant absorbance was attained using $0.8 \mathrm{~mL}$ of $5 \times 10^{-3} \mathrm{M} \mathrm{Ce}(\mathrm{IV})$ solution (Fig. 2).

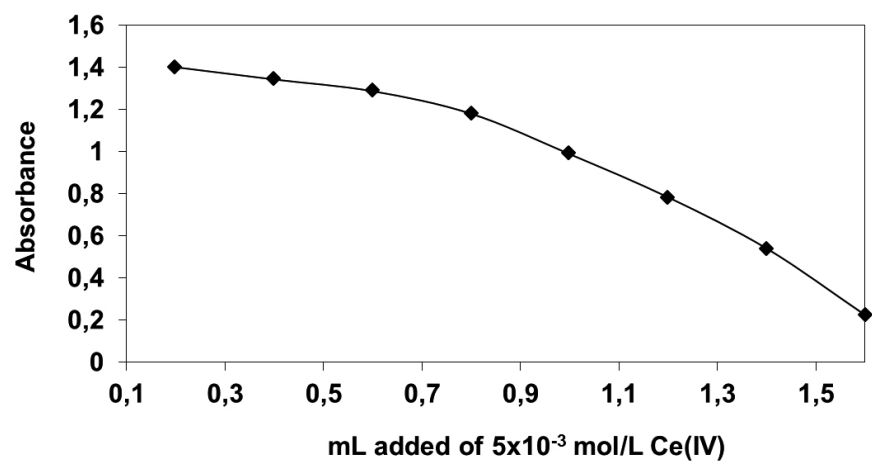

Fig. 2. Effect of $\mathrm{mL}$ added of $5.0 \times 10^{-3} \mathrm{M} \mathrm{Ce}(\mathrm{IV})$ on the reaction product of NALT by spectrophotometriic method.

Effect of time and temperature

The reaction between NALT and Ce(IV) in the presence of $\mathrm{H}_{2} \mathrm{SO}_{4}$ was found to be completely after $5.0 \mathrm{~min}$ of mixing, but $10 \mathrm{~min}$ was sufficient to get maximum absorbance. Raising the temperature does not accelerate the oxidation process and does not give reproducible results, so the optimum temperature is the ambient. The color produced from the reaction between the remaining unreacted $\mathrm{Ce}(\mathrm{IV})$ and methyl orange develops immediately.

Effect of dye concentration

The effect of dye concentration on the intensity of the color developed was tested using different volumes $(0.5-1.6 \mathrm{~mL})$ of $1.0 \times 10^{-3} \mathrm{M}$ methyl orange (MO). It was observed that $1.4 \mathrm{~mL}$ of $\mathrm{MO}$ was necessary for maximum color intensity. After this volume, the absorbance remains constant by increasing the volume of the reagent. The color was found to be stable for at least $3 \mathrm{~h}$ at $25 \pm 2{ }^{\circ} \mathrm{C}$.

\section{Fluorimetric Method}

In general, naltrexone is not fluorescent compound and at the same time it is easily oxidisable species. Ce(IV) is a non-fluorescent metal ion from the lanthanide series. In sulfuric acid medium, Ce(III) shows inherent fluorescence. Because Ce(IV) is easily reduced to Ce(III), it seemed probable that this system would offer good methods for the fluorimietric determination of naltrexone.

Fluorescence spectra

Oxidation of NALT with Ce(IV) in an acid medium yields a highly fluorescent $\mathrm{Ce}(\mathrm{III})$ which exhibits maximum fluorescence at $350 \mathrm{~nm}$ after excitation at $250 \mathrm{~nm}$ (Fig. 3). The oxidation product was found not to be fluorescent. This confirmed the fluorescence induced in the oxidation of the investigated drug with $\mathrm{Ce}(\mathrm{IV})$ was not attributed to its oxidation product; however, it was mainly due to the formation of $\mathrm{Ce}(\mathrm{III})$

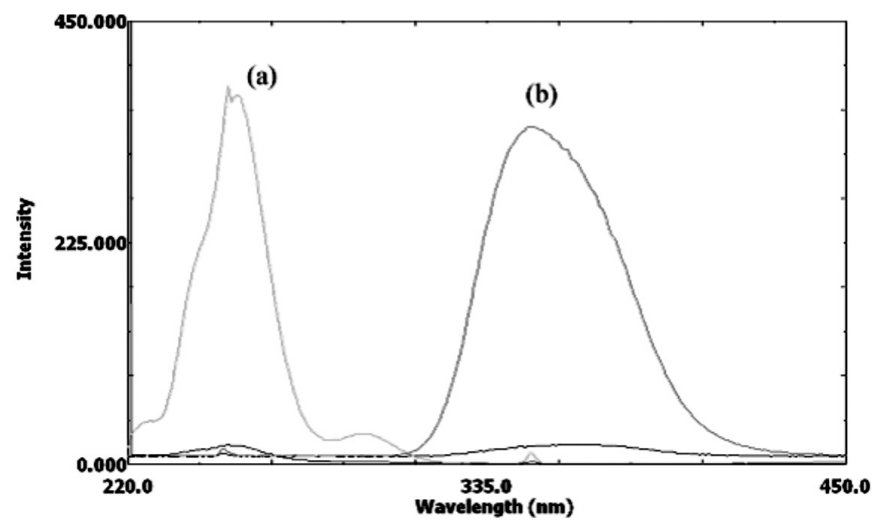

Fig. 3. (a) Excitation and (b) emission spectra for the fluorescent Ce(III) produced by oxidation of $2.4 \mu \mathrm{g} \mathrm{mL} \mathrm{mL}^{-1} \mathrm{NALT}$ with $2.0 \times 10^{-4} \mathrm{M} \mathrm{Ce}(\mathrm{IV})$.

\section{Effect of acid concentration}

The oxidation reaction was conducted in acid medium to avoid the precipitation of hydrated ceric oxide, $\mathrm{CeO}_{2} \times \mathrm{H}_{2} \mathrm{O}$. To select the most appropriate acid for optimum reaction development, acids as $\mathrm{HNO}_{3}, \mathrm{HCl}$ and $\mathrm{H}_{2} \mathrm{SO}_{4}$ were tested to determine the most suitable for optimum reaction development. Either hydrochloric or sulphuric acid could be used as the fluorescence of $\mathrm{Ce}(\mathrm{III})$ is high; however sulphuric acid was selected because blank reading was less than in hydrochloric acid medium. Nitric acid could not be used due to the inhibitory effect of nitrate ions on the fluorescence of $\mathrm{Ce}(\mathrm{IIII}){ }^{16}$ The effect of the concentration of $\mathrm{H}_{2} \mathrm{SO}_{4}$ was studied. The results showed that the fluorescence intensity of system reached the maximum and remained constant when the concentration of $\mathrm{H}_{2} \mathrm{SO}_{4}$ was $0.15-0.3 \mathrm{M}$. So $0.2 \mathrm{M}$ was chosen for further experiments.

Effect of temperature and heating time

The effect of temperature and heating time on the oxidation of NALT with $\mathrm{Ce}$ (IV) was studied by carrying out the reaction at ambient temperature $\left(25 \pm 2^{\circ} \mathrm{C}\right)$ and in a water bath adjusted at elevated temperature ranging from 40 to $100^{\circ} \mathrm{C}$ for different periods of time ranging from 5 to $30 \mathrm{~min}$. The results revealed that the optimum temperature was $100^{\circ} \mathrm{C}$ (Fig. $4 \mathrm{a}$ ). Complete reaction was attained after $10 \mathrm{~min}$ and longer heating time had neither enhancement nor negative effect on the reaction (Fig. 4b). For precisions considerations, $15 \mathrm{~min}$ was selected for subsequent experiments.

\section{Effect of cerium (IV) concentration}

The effect of $\mathrm{Ce}(\mathrm{IV})$ concentration on the fluorescence intensities was optimized as shown in Fig. 5. It was found that maximum relative fluorescence intensity was obtained with a $\mathrm{Ce}(\mathrm{IV})$ concentration of $2.0 \times 10^{-4} \mathrm{M}$. At concentrations lower than this range the fluorescence intensity decreases due to insufficient concentration of $\mathrm{Ce}$ (IV) for oxidation, whereas higher amounts of $\mathrm{Ce}$ (IV) may probably quench the fluorescence and decrease the fluorescence intensity. A volume of $1.0 \mathrm{~mL}$ from this reagent (final concentration of $2.0 \times 10^{-4} \mathrm{M}$ ) was used in the rest of work.

\section{Effect of diluting solvents}

Dilution effect with different solvents on the relative fluorescence intensity revealed that best solvents were water, $\mathrm{MeOH}$, and $\mathrm{EtOH}$ as they were all more or less comparable to each other. However water was the solvent of choice for 
economic and environmental safety purposes. Other solvents as DMSO and acetonitrile showed a distinct sharp decrease in the fluorescence intensity. The induced fluorescence intensity was found stable for more than $3 \mathrm{~h}$.
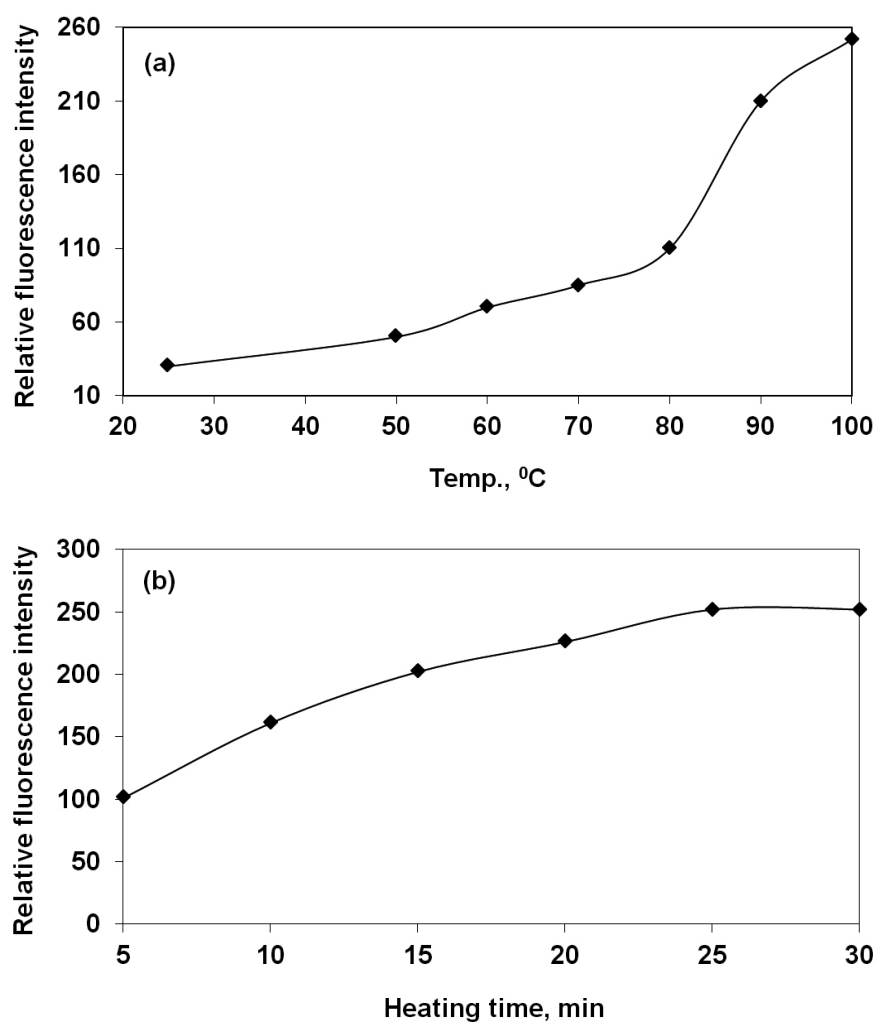

Fig. 4. Effect of temperature (a) and heating time (b) on the fluorescence intensity induced from the oxidation of $2.4 \mu \mathrm{g} \mathrm{mL}{ }^{-1}$ NALT with $2.0 \times 10^{-4} \mathrm{M}$ $\mathrm{Ce}(\mathrm{IV})$.

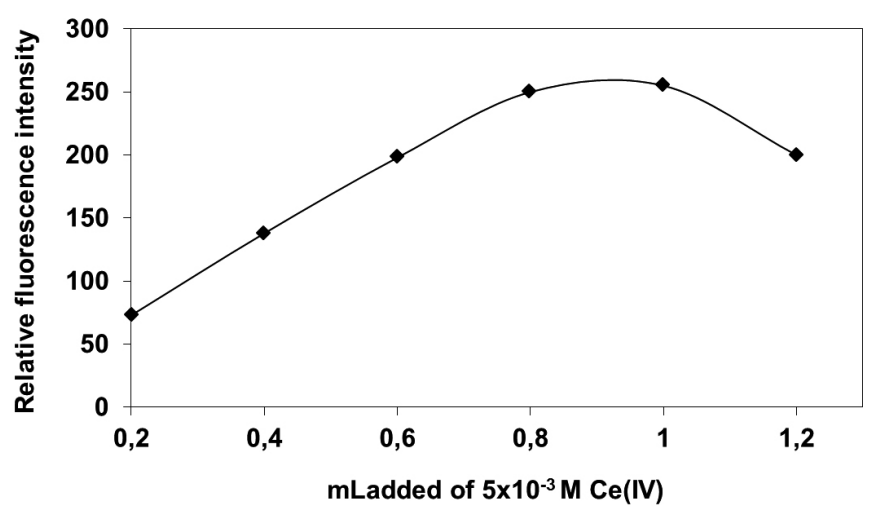

Fig. 5. Effect of $\mathrm{mL}$ added of $5.0 \times 10^{-3} \mathrm{M}$ of $\mathrm{Ce}(\mathrm{IV})$ on the reaction product of NALT by fluorimetric method.

\section{Validation of the Proposed Methods}

Linearity and sensitivity

The calibration curves were constructed for the proposed fluorimetric and spectrophotometric methods over the concentration ranges cited in Table 1. The sensitivity of the proposed methods was evaluated by determining the detection limits; Table 1 presents the results of the statistical analysis of the experimental data: regression equations calculated from calibration graphs along with the standard deviation of the slope, and intercept on the ordinate and the standard deviation of residuals. Small values obtained by these parameters indicate the negligible scatter of the experimental points around the fitted regression lines.
Limits of detection (LOD) and quantitation (LOQ) were calculated as $3.3 \mathrm{\sigma} / \mathrm{S}$ and $10 \sigma / \mathrm{S}$, respectively; where $\sigma=$ standard deviation of the blank and $\mathrm{S}=$ slope of the calibration curve. ${ }^{17}$ The data compiled in Table 1 summarize the characteristics of the calibration curves (Fig. 6).

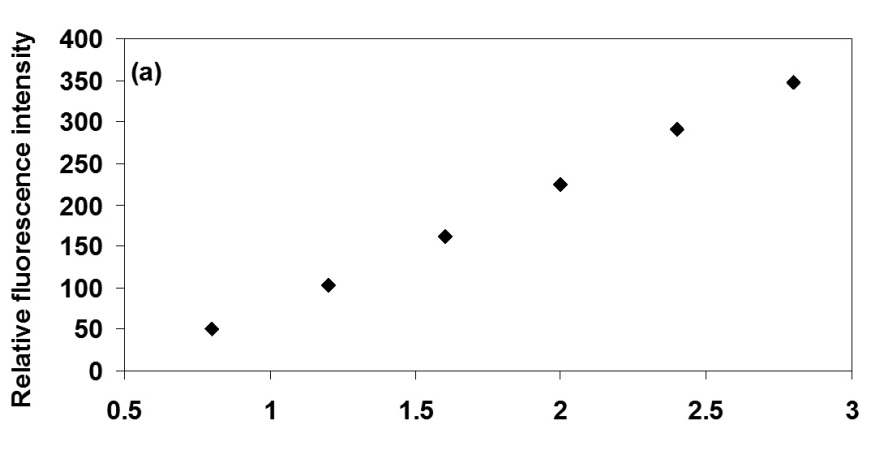

Conc., $\mu \mathrm{g} \mathrm{m \mathbf {L } ^ { - 1 }}$

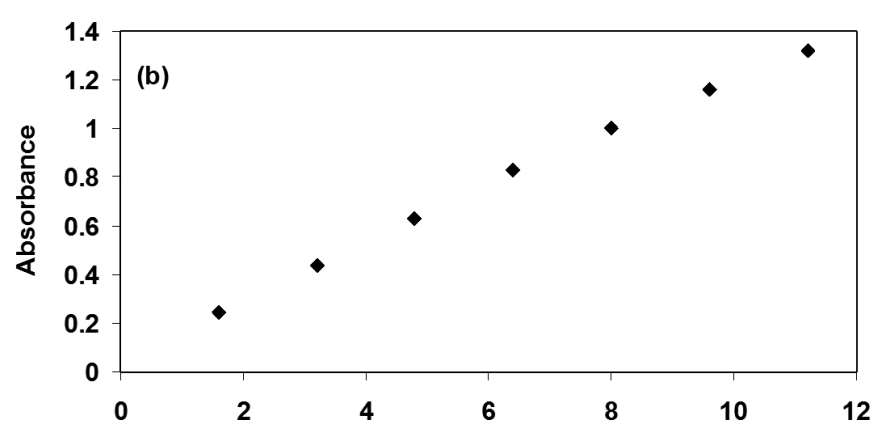

Conc., $\mu \mathrm{g} \mathrm{mL}^{-1}$

Fig. 6. Calibration graphs for determination of the oxidation product of NALT with $2.0 \times 10^{-4} \mathrm{M} \mathrm{Ce}$ (IV) by: (a) fluorimetric and (b) spectrophotometric methods.

Table 1. Optical characteristics and statistical analysis of calibration graphs for the determination of NALT by the proposed methods.

\begin{tabular}{|c|c|c|}
\hline \multirow{2}{*}{ Parameter } & \multicolumn{2}{|c|}{ Method } \\
\hline & Spectrophotometry & Fluorimetry \\
\hline$\lambda_{\text {max }}, \mathrm{nm}$ & 510 & \\
\hline$\lambda_{\mathrm{ex},} \mathrm{nm}$ & & 250 \\
\hline$\lambda_{\mathrm{em},} \mathrm{nm}$ & & 350 \\
\hline Temp. ${ }^{\circ} \mathrm{C}$ & 25 & 100 \\
\hline Linear range, $\mu \mathrm{g} \mathrm{mL}^{-1}$ & $1.6-11.2$ & $0.4-2.8$ \\
\hline Molar absorpitivity, L. $\mathrm{mol}^{-1} \mathrm{~cm}^{-1}$ & $4.73 \times 10^{4}$ & \\
\hline Sandell's sensitivity, $\mu \mathrm{g} \mathrm{cm}^{-2}$ & 0.0079 & \\
\hline Correlation coefficient (r) & 0.9999 & 0.9996 \\
\hline$S_{y / x}$ & 0.0002 & 3.0495 \\
\hline Intercept (a) & 0.0552 & -81.7 \\
\hline Slope (b) & 0.1189 & 153.25 \\
\hline SD of slope $\left(\mathrm{S}_{\mathrm{b}}\right)$ & $3 \times 10^{-5}$ & 2.411 \\
\hline SD of intercept $\left(\mathrm{S}_{\mathrm{a}}\right)$ & $4 \times 10^{-4}$ & 7.781 \\
\hline $\mathrm{LOD}, \mu \mathrm{g} \mathrm{mL} \mathrm{L}^{-1}$ & 0.1831 & 0.0142 \\
\hline $\mathrm{LOQ}, \mu \mathrm{g} \mathrm{mL}^{-1}$ & 0.6042 & 0.0469 \\
\hline
\end{tabular}


Accuracy and precision

In order to determine the accuracy and precision of the proposed method, the assay described under "Procedure for calibration curves" was repeated seven times on the same day to determine the repeatability (intra-day accuracy and precision) and five times on different days to determine the intermediate precision (inter-day accuracy and precision). These assays were performed for three levels of analyte. The results of this study are summarized in Table 2 . The percentage relative standard deviation ( $\% \mathrm{RSD})$ values were $\leq 1.57 \%$ (intra-day) and $\leq 1.63 \%$ (inter-day) indicating high precision of the method. The accuracy of the method was determined by the percent mean deviation from known concentration, by using the formula:

The obtained results are presented in Table 2 . The percentage relative error $(\mathrm{Er} \%)$ and the percentage relative standard deviation (RSD \%) are considered very satisfactory. This level of precision of the proposed methods was adequate for the quality control analysis of naltrexone.

Table 2. Intra-day and inter-day precision and accuracy of the reaction of NALT by the proposed methods.

\begin{tabular}{|c|c|c|c|c|c|c|}
\hline $\begin{array}{c}\text { Frequency of } \\
\text { analysis }\end{array}$ & Method & Taken, $\mu \mathrm{g} \mathrm{mL}^{-1}$ & Found, $\mu \mathrm{g} \mathrm{mL}^{-1}$ & Recovery, \% & $\mathrm{RSD}, \%$ & Er, \% \\
\hline \multirow{6}{*}{ 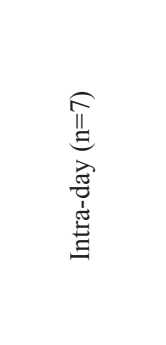 } & \multirow{3}{*}{ Spectrophotometry } & 3.2 & 3.19 & 99.98 & 1.0772 & -0.012 \\
\hline & & 6.4 & 6.40 & 100.03 & 1.4950 & 0.03 \\
\hline & & 9.6 & 9.59 & 99.99 & 0.2736 & -0.004 \\
\hline & \multirow{3}{*}{ Fluorimetry } & 0.8 & 0.79 & 99.99 & 1.5724 & -0.002 \\
\hline & & 2 & 1.99 & 99.99 & 0.8534 & -0.006 \\
\hline & & 2.8 & 2.79 & 99.99 & 0.3700 & -0.004 \\
\hline \multirow{6}{*}{ 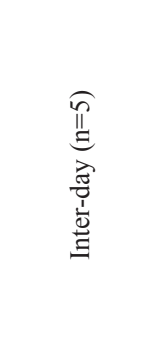 } & \multirow{3}{*}{ Spectrophotometry } & 3.2 & 3.19 & 99.98 & 1.6335 & -0.014 \\
\hline & & 6.4 & 6.39 & 99.99 & 0.8736 & -0.002 \\
\hline & & 9.6 & 9.59 & 99.99 & 0.4349 & -0.001 \\
\hline & \multirow{3}{*}{ Fluorimetry } & 0.8 & 0.81 & 101.25 & 2.5003 & 0.014 \\
\hline & & 2 & 2.01 & 100.50 & 0.7186 & 0.018 \\
\hline & & 2.8 & 2.81 & 100.36 & 1.7738 & 0.01 \\
\hline & & & & & & \\
\hline
\end{tabular}

Table 3. Determination of NALT in tablet and biological fluids using the proposed methods.

\begin{tabular}{|c|c|c|c|c|c|c|c|c|}
\hline Sample & \multicolumn{4}{|c|}{ Spectrophotometry } & \multicolumn{4}{|c|}{ Fluorimetry } \\
\hline \multirow{2}{*}{$\begin{array}{l}\text { Deltrexone } \\
50 \mathrm{mg} / \text { tablet }\end{array}$} & 4.8 & 4.75 & 99.01 & 1.4503 & 2.0 & 2.06 & 103.05 & 2.1763 \\
\hline & 8.0 & 7.92 & 99.09 & 1.1327 & 2.8 & 2.84 & 101.42 & 1.9994 \\
\hline Serum & 8.0 & 8.16 & 102.06 & 2.6129 & 2.8 & 2.81 & 100.63 & 0.8694 \\
\hline \multirow{2}{*}{ Urine } & 4.8 & 4.79 & 99.97 & 0.3143 & 2.0 & 2.02 & 101.30 & 1.7526 \\
\hline & 8.0 & 8.18 & 102.30 & 2.1844 & 2.8 & 2.79 & 99.93 & 1.0204 \\
\hline
\end{tabular}

\section{Interference studies}

The effects of common excipients and additives were tested for their possible interferences in the assay of NALT and the results are shown in Table 3. It is evident that the excipients and additives did not interfere in the determination of NALT.

\section{Robustness and ruggedness.}

Robustness was examined by evaluating the influence of small variation of method variables, including concentration of analytical reagents and reaction time on the performance of the proposed methods. In these experiments, one parameter was changed whereas the others were kept unchanged, and the recovery percentage was calculated each time. It was found that small variation of method variables did not significantly affect the procedures. This provided an indication for the reliability of the proposed methods during its routine application for the analysis of NALT. Ruggedness was also tested by applying the proposed methods to the assay of NALT using the same operational conditions but using two different instruments at two different laboratories and different elapsed time. Results obtained from lab-to-lab and day-to-day variations were found to be reproducible, the full range of recovery values was $99.98-101.25 \%$ for the proposed methods.

\section{Analysis of tablets}

The proposed methods were applied to the determination of NALT in detrexone tablets. The results obtained are satisfactorily accurate and precise as indicated by the excellent $\%$ recovery and RSD $\%$ less than $2.2 \%$ (Table 3 ). 
Analysis of spiked serum and urine samples

The high sensitivity of the proposed methods allowed the determination of NALT in spiked urine and serum samples. The recovery studies were carried out on the sample, where known amounts of NALT were added and the results of spiked urine and serum samples are given in Table 3. Recovery was from 99.93 to 102.30 for urine and 100.21 to 102.97 for serum. This indicates good level of precision and accuracy.

\section{CONCLUSION}

The suggested spectrophotometric and fluorimetric methods have the advantage of being simple, accurate, sensitive and suitable for routine quality control of pure drug and in pharmaceutical formulation without risk of interference used by excipients expected to present in formulation and could be applied for the assay of NALT in biological fluids. The fluorimetric method exhibits the highest sensitivity that makes it possible to measure concentrations down to $0.4 \mu \mathrm{g} \mathrm{mL}-1$. This study is the first report for the determination of NALT.

\section{REFERENCES}

1. A. M. Washton, M. S. Gold, A. C. Pottash, Adv. Alcohol Subst. Abuse 4, 89, (1984).

2. C. P. O'Brien, R. A. Greenstein, G. E. Woody, Update on naltrexone treatment, in: The International Challenge of Drug Abuse, R.C. Peterson, ed., NIDA Research Monograph No. 19, National Institute of Drug Abuse, Rockville, MD, 1978; pp. 315.

3. M. E. Wall, D. R. Brine, M. Perez-Reyes, Drug Metab. Dispos. 9, 369, (1981).

4. S. Brünen, R. Krüger, S. Finger, F. Korf, F. Kiefer, K. Wiedemann, K. J Lackner, C. Hiemke, Anal. Bioanal. Chem. 396, 1249, (2010)

5. A. F. Davidson, T. A. Emm, H. J. Pieniaszek Jr, J. Pharm. Biomed. Anal. 14, 1717, (1996) l-n
6. W. J. Hurst, I. S. Zagon, H. Y. Aboul-Enein, Pharmazie 54, 595, (1999)

7. K. Kambia, S. Bah, T. Dine, R. Azar, P. Odou, B. Gressier, M. Luyckx, C. Brunet, L. Ballester, M. Cazin, J. C. Cazin, Biomed. Chromatogr. 14, 151, (2000).

8. E. F. O'Connor, S. W. T. Cheng, W. G. North, J. Chromatogr. Biomed. Appl. 491, 240, (1989).

9. K. Vereby, M. J. Kogan, A. DePace, S. J. Mulle, J. Chromatogr. A 118, 331, (1976).

10. K. Verebey, _NIDA research monograph 28, 36, (1981).

11. R. Mehrdad, A. Khosrou, D. Rassoul, V.-G. Sanaz, A. Mohsen, Chromatographia 70, 1491, (2009)

12. S. Valiveti, B. N. Nalluri, D. C. Hammell, K. S. Paudel, A. L. Stinchcomb, J. Chromatogr. B 810, 259, (2004)

13. S. S. Iyer, G. E. Kellogg, H. A. T. Karnes, J. Chromatogr. Sci. 45, 694, (2007).

14. M. H. Slawson, M. Chen, D. Moody, S. D. Comer, E. S. Nuwayser, W. B. Fang, R. L. Foltz, J. Anal. Toxicol. 31, 453, (2007).

15. P. Baumann, C. Hiemke, S. Ulrich, G. Eckermann, I. Gaertner, M. Gerlach, H. J. Kuss, G. Laux, B. Müller-Oerlinghausen, M. L. Rao, P. Riederer, G. Zernig, Pharmacopsy. 37, 243, (2004).

16. G. H. Jeffery, J. Bassett, J. Mendham, R. C. Dennery. Vogel's Textbook of Quantitative Chemical Analysis. Fifth ed, the Bath Press, Great Britain, 1989.

17. J. C. Miller and J. N. Miller. Significance tests in statistics for analytical chemistry, 3rd ed., Hardwood, Chichester, 1993. 